\title{
A Importância do Estudo das Linguagens para a Comunicação Não Violenta
}

\author{
La Importancia del Estudio de los Lenguajes para la Comunicación No \\ Violenta
}

The Importance of Studying Languages for Non-Violent Communication

\author{
Rodrigo Bilieri de Almeida ${ }^{1}$
}

\begin{abstract}
Resumo
O presente trabalho busca apresentar um entendimento interdisciplinar da comunicação não violenta, aplicando a este método da Psicologia e Negociações os estudos da Linguística e das Letras. Este artigo pretende defender uma importante e necessária conexão da teoria da comunicação não violenta de Marshall Rosenberg com os estudos das formas linguísticas (linguagem verbal falada, linguagem verbal escrita e linguagem não verbal corporal). Não menos importante, esta publicação apresenta e conceitua todos estes aspectos, brevemente, na sua introdução. Assim, questiona-se o quanto podemos nos comunicar de maneira não violenta considerando apenas os aspectos de uma linguagem (e.g. verbal) sem aplicar os estudos amplos das outras formas de comunicação (e.g. corporal). Da pesquisa, resulta a compreensão de que, para se comunicar de modo não violento, não é suficiente apenas a intenção ou o sentido, mas inclusive saber transmitir essa expressão em uma proposição linguística coerente. Outrossim, considerando um diálogo, além de estrutura frasal adequada à pacificação, a linguagem corporal deve sinalizar essa mesma mensagem. Quanto aos aportes bibliográficos, o artigo analisa literaturas acadêmicas e científicas, sobretudo de estudos linguísticos. A referência principal é o livro Comunicação Não Violenta: técnicas para aprimorar relacionamentos pessoais e interpessoais. O presente trabalho empregou o método hipotético-dedutivo. A pesquisa é qualitativa, básica, explicativa e bibliográfica.
\end{abstract}

Palavras-Chave: Comunicação Não Violenta; Letras; Linguística; Formas da Linguagem.

\section{Resumen}

El presente trabajo busca presentar un entendimiento interdisciplinario de la comunicación no violenta, aplicando a este método de la Psicología y Negociaciones los estudios de la Lingüística y de las Letras. Este artículo pretende defender una importante y necesaria conexión de la teoría de la comunicación no violenta de Marshall Rosenberg con los estudios de las formas lingüísticas (lenguaje verbal hablada, lenguaje verbal escrito y lenguaje no verbal corporal). No menos importante, esta publicación presenta y conceptualiza todos estos aspectos, brevemente, en su introducción. Así, se cuestiona cuánto podemos comunicarnos de manera no violenta considerando sólo los aspectos de un lenguaje (e.g. verbal) sin aplicar los estudios amplios de las otras formas de comunicación (e.g. corporal). De la investigación, resulta la comprensión de que, para comunicarse de modo no violento, no es suficiente sólo la intención o el sentido, sino incluso el conocimiento de transmitir esa expresión en una proposición lingüística coherente. Igualmente, considerando un diálogo, además de estructura frasal adecuada a la pacificación, el lenguaje corporal debe señalar ese mismo mensaje. En cuanto a los aportes bibliográficos, el artículo analiza literaturas académicas y científicas, en especial de estudios lingüísticos. La referencia principal es el libro Comunicación No Violenta: Un Lenguaje de Vida. El presente trabajo empleó el método hipotético-deductivo. La investigación es cualitativa, básica, explicativa y bibliográfica.

Palabras claves: Comunicacíon No Violenta; Letras; Lingüística; Formas del Lenguaje.

\footnotetext{
${ }^{1}$ Graduando em Direito; Universidade Federal do Rio Grande - FURG; Rio Grande, Rio Grande do Sul, Brasil; rbilieridealmeida@gmail.com.
} 


\begin{abstract}
The present work seeks to present an interdisciplinary understanding of nonviolent communication, applying to this method of Psychology and Negotiations the studies of Linguistics and Letters. This article intends to defend an important and necessary connection of Marshall Rosenberg's theory of nonviolent communication with studies of forms of language (spoken verbal language, written verbal language and nonverbal body language). Not less important, this publication presents and conceptualizes all these aspects briefly in its introduction. Thus, it is questioned how much we can communicate in a non-violent way considering only the aspects of one language (e.g. verbal) without applying the broad studies of other types of communication (e.g. body language). From the research, it results the understanding that, in order to communicate in a non-violent way, it is not sufficient to intend or mean that way, but also to know how to convey that expression in a coherent linguistic proposition. Moreover, considering a dialogue, in addition to a phrase structure appropriate to pacification, body language should signal this same message. As for the bibliographical contributions, the article analyzes academic and scientific literatures, mostly of linguistic studies. The main reference is the book Nonviolent Communication: A Language of Life. The present work employed the hypothetical-deductive method. The research is qualitative, basic, explanatory and bibliographical.
\end{abstract}

Keywords: Nonviolent Communication; Letters; Linguistics; Types of Communication.

\title{
1. Introdução
}

O objetivo deste trabalho é aprofundar os estudos derivados da Comunicação Não Violenta (CNV), buscando acrescentar uma reflexão sobre a importância dos estudos da Linguagem (a partir de sub-áreas do conhecimento como Letras e Linguística) para permitir a eficácia plena e multilongitudinal deste método de comunicação. Nesse sentido, esta pesquisa tende à interdisciplinariedade, acrescentando à CNV as contribuições científicas de Letras e Linguística no estudo da linguagem, sem, contudo, retirar o aspecto psicológico e negocial desse método.

Mais especificamente, esta produção analisará a estrutura das formas linguísticas (linguagem verbal falada, linguagem verbal escrita e linguagem não verbal corporal), agrupadas em dois focos - a estrutura frasal para a fala e escrita; e gestos, fisionomia e postura para o corpo.

A comunicação empática, método idealizado no livro Comunicação Não Violenta: técnicas para aprimorar relacionamentos pessoais e interpessoais, de Marshall Rosenberg, é um conjunto de técnicas discursivas para se relacionar de forma produtiva, significativa e benéfica com outras pessoas. É a síntese de uma filosofia de vida baseada em consciência, afeto, empatia, generosidade e respeito. A partir da CNV, conflitantes podem restabelecer um vínculo comunicativo fragilizado ou até mesmo rompido pelo calor do conflito, além de solucionarem o impasse da forma que termine melhor para ambos.

Trata-se de um método preocupado com a comunicação, sendo que a linguagem é o sistema da comunicação: 
Communication refers to the transmission and reception of INFORMATION (a 'message') between a source and a receiver using a signalling system: in linguistic contexts, source and receiver are interpreted in human terms, the system involved is a LANGUAGE, and the notion of response to (or acknowledgement of) the message becomes of crucial importance (CRYSTAL, 2008, p. 89).

Uma vez entendida a linguagem como o "Sistema organizado através do qual é possível se comunicar por meio de sons, gestos, signos convencionais" (DICIO DICIONÁRIO ONLINE DE PORTUGUÊS, 2018) - i.e., o instrumento da comunicação -, Rosenberg desde cedo se dedica em sua bibliografia à análise gramatical e sintática do discurso. No referido magnum opus, muitos são os exemplos de frases e orações que se devem evitar, e exemplos daquelas que são estimuladas; bem como diversas construções verbais (ROSENBERG, 2006, pp. 59-61):

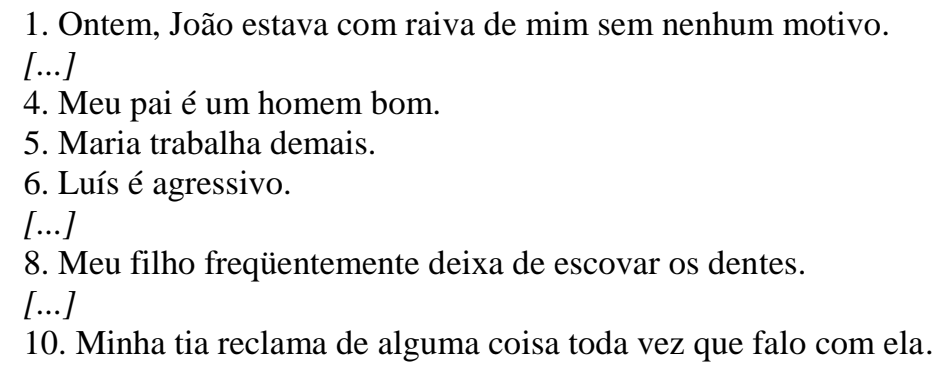

Segundo o autor, pelos motivos que se revisarão mais tarde, todas estas construções verbais seriam evitáveis pela CNV, pela potência agressiva que podem desencadear em um diálogo. Nesse diapasão, parece essencial o estudo da linguagem e de como estruturar um pensamento em palavras, para poder se expressar efetivamente de forma não violenta.

$\mathrm{O}$ autor reconhece em muito a importância da linguagem e da palavra para o advento da comunicação não violenta, como expõe: "Enquanto estudava os fatores que afetam nossa capacidade de nos mantermos compassivos, fiquei impressionado com o papel crucial da linguagem e do uso das palavras" (ROSENBERG, 2006, p. 21).

Assim, é de suma importância a realização de uma ponte entre estudos da linguagem e a comunicação não violenta, algo que Rosenberg já promove ao longo de sua obra, ao analisar os discursos e reuni-los em Linguagem Girafa e Linguagem Chacal. Porém, é necessário aprofundar ainda mais este ponto tão crucial para o estabelecimento da comunicação, sobretudo nos aspectos da linguagem corporal, que restaram ignorados pela produção do autor. É evidente que a sua teoria não possuía o recorte temático de estudar os sinais dos gestos e posturas corporais, mas o próprio psicólogo admite a complexidade da comunicação para se apenas analisar sua natureza violenta ou pacífica na linguagem verbal: 
Entretanto, a CNV não é meramente uma linguagem, nem um conjunto de técnicas para usar as palavras; a consciência e a intenção que a CNV abrange podem muito bem se expressar pelo silêncio (uma característica do estar presente), pela expressão facial e pela linguagem corporal (ROSENBERG, 2006, p. 33).

Visto que a linguagem corporal é de certo modo onipresente, por não se ausentar mesmo quando a linguagem verbal se cala $^{2}$, resta cristalina a necessidade de se abordar a CNV a partir desta forma de comunicação.

Nesse contexto, o problema que impulsiona esta pesquisa é a dúvida sobre o quanto de pacificação e cooperação podemos transmitir em nossas narrativas, empenhados à solução de uma hostilidade, sem recorrer ao usufruto de todas as formas de comunicação - desde o verbo até o corpo.

Ante o exposto, este trabalho desenvolverá a relação da comunicação de Rosenberg com a Linguagem em dois tópicos gerais: primeiramente, a análise de estruturas frasais aptas a emergir uma comunicação não violenta, dentro de narrativas e discursos falados e escritos; e na segunda seção, a análise de aspectos da linguagem corporal que, de mesma maneira, consigam comunicar uma mensagem não-violenta entre as pessoas.

Quanto aos aportes bibliográficos, o artigo analisa literaturas acadêmicas e científicas, sobretudo de estudos linguísticos. A referência principal é o livro Comunicação Não Violenta: técnicas para aprimorar relacionamentos pessoais e interpessoais. O presente trabalho empregou o método hipotético-dedutivo. A pesquisa é qualitativa, básica, explicativa e bibliográfica.

\section{Estruturas frasais para uma linguagem verbal não-violenta}

\subsection{Os julgamentos moralizantes e os adjetivos}

Considera-se linguagem verbal aquela comunicação que emprega palavras na transmissão de suas mensagens. A linguagem verbal tradicionalmente ocorre por meio da fala ou da escrita.

Para Rosenberg (2006, p. 37), quando recorremos a este tipo de linguagem, devemos evitar construções de texto que exprimam julgamentos moralizantes:

Um tipo de comunicação alienante da vida é o uso de julgamentos moralizadores que subentendem uma natureza errada ou maligna nas pessoas que não agem em consonância com nossos valores. Tais julgamentos aparecem em frases como: "O teu problema é ser egoísta demais", "Ela é preguiçosa", "Eles são preconceituosos",

\footnotetext{
2 Segundo Pease \& Pease (s/a, p. 6), “A comunicação não verbal, geralmente, mantém uma relação de interdependência com a interação verbal. / Com frequiência as mensagens não verbais têm mais significação que as mensagens verbais. / Em qualquer situação comunicativa, a comunicação não verbal é inevitável".
} 
"Isso é impróprio". Culpa, insulto, depreciação, rotulação, crítica, comparação e diagnósticos são todos formas de julgamento.

De acordo com o autor, moraliza-se quando alguém julga características de outros indivíduos a partir de suas próprias perspectivas, seus valores individuais. "Nossa atenção se concentra em classificar, analisar e determinar níveis de erro, em vez de fazê-lo no que nós e os outros necessitamos e não estamos obtendo" (ROSENBERG, 2006, p. 38). Esse julgamento é absolutamente relativo e subjetivo, pois criticamos os outros por não estarem se comportando da maneira como queríamos ou que melhor nos agradaria. Uma pessoa A, que demonstre afeto diversas vezes no dia, pode ser vista como "carente" por uma pessoa B, que não demonstre afeto com mesma periodicidade; todavia, um indivíduo $\mathrm{C}$, que manifeste afetividade de forma parecida em relação à pessoa $\mathrm{A}$, pode observá-la como um sujeito "carinhoso" ou "amoroso", e ver B como "frio" ou "insensível”.

Nessa seara, Rosenberg menciona diversos exemplos de orações em que se evidenciam julgamentos moralizantes: "Ela é preguiçosa", "Eles são preconceituosos" e "Isso é impróprio" (como supracitado) e, em sequência, "Luís é agressivo" (op. cit., p. 59).

Em uma análise morfológica destas estruturas frasais, identifica-se que uma linguagem verbal violenta, que expresse julgamentos moralizantes, costuma decorrer da seguinte construção: Sujeito + verbo "Ser" + adjetivo, sendo que o sujeito da oração é a pessoa que sofre o julgamento, normalmente o ouvinte da frase ou o conflitante em um problema.

É lógico que o julgamento moralizante pode se expressar com outros verbos que não o verbo Ser, como em "Você está maluca!" ou "Fulano parece um idiota!". Além disso, pode-se moralizar alguém com frases mais sucintas, inclusive sem verbo ("Homem covarde! Mulher indecente! Criança chata!"); ou, ainda mais breve, quando, direcionadas ao ouvinte - que necessariamente deve ser o alvo da crítica - profere-se: "Burra!” ou "Feio!".

A partir desta minúcia das frases originais, percebe-se que o adjetivo é o núcleo sintático do julgamento moralizante. Sem o adjetivo, não se pode reputar a alguém (o sujeito) a crítica a ser transmitida. Outrossim, depende da escolha do adjetivo e seu sentido léxico o impacto agressivo deste julgamento, uma vez que "Meu pai é um homem bom" (p.ex.), embora seja uma forma de julgamento, uma avaliação (e não observação), não tem cunho pejorativo capaz de ofender alguém e, desta maneira, comunicar-se violentamente.

Para Paschoalin \& Spadoto (2008, p. 56), "Adjetivo é a palavra que indica características dos seres"; "Ele [o adjetivo] é empregado na descrição do ser". Assim, não seria possível que um avaliador apontasse as características de alguém sob a sua análise, sem o recurso linguístico desta classe gramatical. 
Portanto, para uma comunicação não violenta por intermédio da linguagem verbal, deve-se evitar ao máximo e dentro do possível o emprego de adjetivos, sobretudo em estruturas frasais Sujeito + Verbo "Ser" e aqueles com significado pejorativo. Contudo, não se está a referir a todos os adjetivos existentes na Língua Portuguesa: apenas aqueles que expressem qualidades e aspectos dos seres. Parafraseando Paschoalin e Spadoto (op. cit., p. 56), os adjetivos também podem comunicar estados ("Minha irmã está preocupada”) e locais de origem ("Tenho muitos amigos cearenses"). Esses adjetivos, a princípio, não podem servir de recurso para uma comunicação violenta.

Aliás, esses diferentes adjetivos explicam por que os verbos "Estar" ou "Parecer" podem substituir "Ser" na construção moralizante Sujeito + "Ser" + Adjetivo. Isso ocorre porque o verbo "Estar", embora não deixe de expor um estado (momento), nesse caso, não se liga a um adjetivo que expresse um estado de sentimento como em "preocupada", mas sim, um aspecto ou qualidade passageiro - "Você está maluca".

Por fim, atenta-se que, a estrutura frasal moralizante dos exemplos é minimalista. $\mathrm{Ou}$ seja, as orações podem prescindir a equação Sujeito + "Ser" + Adjetivo, com a inserção de outras classes gramaticais (um artigo, uma preposição ou um advérbio) e de complementos ou adjuntos nominais. $\mathrm{O}$ sujeito pode ser colocado na forma de um substantivo ou um pronome e precisa ser definido.

\subsection{A comparação, as locuções e a conjunção "como"}

Para Rosenberg (2006, p. 41), outra forma de julgamento é o uso de comparações. Comparar-se a outras pessoas nos deixaria infelizes. Dessa maneira, todo arcabouço linguístico que contribua para expressar comparações deve ser evitado.

Gramaticalmente, é recomendável não utilizar adjetivos e advérbios em grau comparativo entre seres diferentes, como em: "Aquele garoto é tão burro quanto uma porta" ou "Sua mulher toma iniciativas pior que você". Tal entendimento serve tanto para o grau comparativo de igualdade quanto de superioridade e inferioridade, os três tipos de grau de acordo com Paschoalin \& Spadotto (2008, p. 68 e 168). Nesse último caso, a comunicação pode ser ainda mais violenta, por utilizar-se corriqueiramente expressões como "pior que", per si ofensiva e negativa.

Sintaticamente, restam desaconselhadas as orações subordinadas adverbiais comparativas (Cf. Paschoalin \& Spadotto, 2008, p. 329). Por exemplo, em uma situação de conflito familiar entre o casal e um filho de 12 anos, em que este último está a chorar descontrolavelmente e a fazer barulho de madrugada, uma linguagem Chacal dos pais seria: 
"Você não cresceu nada!/ [Você] Chora como um bebê [chora]!". Mesmo que o comportamento do menino seja muito desagradável e desrespeitoso aos seus responsáveis, a comunicação empenhada por estes é similarmente desrespeitosa e pouco (senão nada) efetiva em convidar o infantojuvenil a repensar a sua atitude, ou a pensar em uma solução do impasse que o fez sentir-se triste. A comunicação violenta empregada também é inútil em demonstrar ao filho as necessidades dos pais no caso concreto, e não transmite interesse do casal em compreender (ou tentar) os sentimentos de seu descendente. Muito pelo contrário: provavelmente o menor retribuirá o "ataque" realizado pelos genitores em linguagem Chacal em uma violência recíproca que se agravará gradativamente, afastando ainda mais as gerações.

Em outro cenário, considerando um casal de meia idade em que um cônjuge está insatisfeito com o peso do(a) parceiro(a), expressões como "Você mais come do que respira", além de presumivelmente exageradas, soam hostis para o sujeito. No caso de uma comunicação verbal falada, a agressividade pode vir intensificada por uma entonação irônica, em tom grave e voz alta. Obviamente, as chances de surgir um diálogo próspero e pacífico a partir desta iniciação de fala são bastante reduzidas.

Assim, de forma resumida, adverte-se cautela no uso das subsequentes locuções: "tão... quanto", "mais... (do) que", "menos... (do) que", "melhor (do) que”, "pior (do que)", "tal qual", "tal como", "tanto quanto", "que nem" e sinônimos. A expressão "como se fosse (um)(a)" também é evitável. A conjunção "como" só é desestimulada quando exerce a função de conectivo comparativo. Quando expressa conformidade (e.g. "Respondi as questões da lição como minha professora ensinou") ou causalidade ("Como estava chovendo, ninguém saiu de casa"), não ser faz admoestações.

\subsection{A responsabilidade e os verbos}

De acordo com Marshall Rosenberg (2006, pp. 42-3), outro problema da comunicação não compassiva é a negação de responsabilidade pelo comunicador, em relação a uma situação indesejada; às vezes, inclusive, transmitindo a responsabilidade ao outro:

O uso corriqueiro da expressão "ter de" (como em "Há algumas coisas que você tem de fazer, quer queira, quer não") ilustra de que modo a responsabilidade pessoal por nossos atos fica obscurecida nesse tipo de linguagem. A expressão "fazer alguém sentir-se" (como em "Você me faz sentir culpado") é outro exemplo da maneira pela qual a linguagem facilita a negação da responsabilidade pessoal por nossos sentimentos e pensamentos.

$[\ldots]$

Negamos responsabilidade por nossos atos quando os atribuímos a: 
- forças vagas e impessoais ("Limpei meu quarto porque tive de fazê-lo");

- nossa condição, diagnóstico, histórico pessoal ou psicológico ("Bebo porque sou alcoólatra");

- ações dos outros ("Bati no meu filho porque ele correu para a rua");

- ordens de autoridades ("Menti para o cliente porque o chefe me mandou fazer isso");

• pressão do grupo ("Comecei a fumar porque todos os meus amigos fumavam");

- políticas, regras e regulamentos institucionais ("Tenho de suspender você por conta dessa infração; é a política da escola");

- papéis determinados pelo sexo, idade e posição social ("Detesto ir trabalhar, mas vou porque sou pai de família");

• impulsos incontroláveis ("Fui tomado por um desejo de comer aquele doce").

Nesse diapasão, alguns verbos e locuções verbais facilitam construções textuais de negação de responsabilidade, o que, por sua vez, atrapalha a solução de um conflito e cede espaço para o advento de uma comunicação violenta. São eles: "ter de“, "ter de fazer", "fazerme" e "dever". O uso destas expressões enseja um maior cuidado para um comunicador consciente. Também mascaram a responsabilidade: os pronomes impessoais e a expressão "Sinto-me... porque" seguida de sujeito alheio ao falante, como "você", "eles" e "alguém" (ROSENBERG, 2006, p. 83).

Ao mesmo tempo, estruturas que atribuam culpa a outra pessoa ("Porque você...", "Por conta de sua...", “...por causa tua", "Você me faz..." "fazer alguém sentir-se" etc.) impedem uma comunicação compassiva.

Ademais, não somente a negação de responsabilidade própria e a responsabilização do outro por atos nossos são reprováveis, como também a acusação ou repreensão do outro por um comportamento que ele é responsável. A expressão "Mas por que..." terminada em um ponto interrogativo tem naturalmente uma conotação agressiva, significando um sermão mais do que uma pergunta - "Mas por que você fez isso?".

Consoante Rosenberg (2008, pp. 44-5), "podemos substituir uma linguagem que implique falta de escolha por outra que reconheça a possibilidade de escolha", sendo preferíveis estruturas como "eu opto por... [situação indesejada] porque... [minha necessidade]". A consciência da responsabilidade pelos próprios atos faz as pessoas serem mais cautelosas e corretas em seus comportamentos, em detrimento de simplesmente fazê-los porque são obrigadas, situação em que teoricamente não precisariam assumir pelas condutas praticadas. 
Ainda, sobre a expressão "fazer alguém sentir-se", embora esta locução verbal não seja recomendada durante resoluções de conflito, o verbo "Sentir" ajuda muito a promoção da CNV. A exposição de sentimentos é primordial para uma comunicação empática. Todavia, o verbo é polissêmico. Quando "Sentir" for empregado no sentido de "Pensar", "Crer" ou “Achar”, não surte o efeito na comunicação não violenta, conforme Rosenberg (2006, pp. 689) explica distintamente:

Uma confusão comum gerada por nossa linguagem é o uso do verbo sentir sem realmente expressar nenhum sentimento. Por exemplo, na frase "Sinto que não consegui um acordo justo", a palavra sinto poderia ser mais precisamente substituída por penso, creio ou acho. Em geral, os sentimentos não estão sendo claramente expressos quando a palavra sentir é seguida de:
A. Termos como que, como, como se:
"Sinto que você deveria saber isso melhor do que ninguém".
"Sinto-me como um fracassado".
"Sinto como se estivesse vivendo com uma parede".
B. Vocábulo que seguido de pronomes como eu, ele, ela, eles, isso etc.:
"Sinto que eu tenho de estar constantemente disponível".
"Sinto que isso é inútil".
C. Vocábulo que seguido de nomes ou palavras que se referem a pessoas:
"Sinto que Lúcia tem sido bastante responsável".
"Sinto que meu chefe está me manipulando".

\subsection{A CNV e a linguagem figurada}

Além do que leciona Marshall Rosenberg, este trabalho entende que algumas figuras de linguagem (ou figuras de estilo) não são compatíveis com os princípios da comunicação empática.

Segundo Paschoalin \& Spadotto (2008, p. 500), comparação (ou símile) “é a aproximação de dois termos, ligados por meio de um conectivo, entre os quais existe uma relação de semelhança. A aproximação entre eles busca realçar determinada qualidade do primeiro termo". Já que, como previamente exposto, a comparação é uma forma de julgamento, recomendasse a exclusão deste recurso estilístico nos diálogos de mediação e conciliação. A símile pode ser verbalizada pelo verbo "Parecer" ("Você não se mexe pra nada, parece uma pedra!") ou pelos recursos citados na seção 2.2..

Além disso, a Metáfora - "termo empregado com significado de outro por haver entre ambos uma relação de semelhança. [...] uma comparação subentendida, sem a presença do conectivo" (PASCHOALIN \& SPADOTTO, 2008, loc. cit.) -, por exercer uma função análoga à Símile, também é desaconselhada. Normalmente, ocorre na expressão Sujeito + Verbo "Ser" + Numeral + Substantivo, sendo o substantivo empregado em conotação 
pejorativa: "Ela é uma porca". Assim como nos julgamentos moralizantes por intermédio de adjetivos, o verbo "Ser" pode ser trocado pelo verbo "Estar".

Ademais, resta desincentivada a Antífrase ou Ironia, que consiste em "afirmar o contrário do que se pensa, geralmente num tom depreciativo e sarcástico" (ALMEIDA, 2010, p. 479). Esta maneira de expressão falta com a sinceridade e pode promover confusão ao receptor da mensagem. Ela impede uma comunicação aberta e honesta, em que as partes expõem suas necessidades e sentimentos e confiam uma na outra. Na situação hipotética de um amigo esperar o outro chegar em uma reunião marcada, e este aparecer atrasado, a mensagem irônica do primeiro "Chegou cedo, hein!” não é, a priori, apropriada para manifestar descontentamento sensível e, assim, por falta de diálogo pacífico, não pode resolver o problema em repetições futuras. Em outra ocasião, a frase "Nossa, adoro tanto quando você suja a pia e sai sem lavar!”, dita por um colega de quarto insatisfeito com os hábitos domésticos do outro morador, dificilmente fará este último repensar suas atitudes. Isto, pois o residente que deixou a louça suja na pia foi ofendido e, naturalmente, não tentará ser bom ou agradável para quem o ofendeu.

De sua banda, o Disfemismo também é nocivo à CNV. Conforme Daniela Otsuka (2010), “Considerado o oposto do Eufemismo, o Disfemismo é uma figura de linguagem que consiste no emprego de expressões ou termos rudes, sarcásticos, provocativos, humilhantes que são usados para definir pessoas ou situações". Por exemplo, em uma afirmação, em vez de se referir "As pessoas gordas..." ou "Os gordos..." (o que se trata de uma qualidade, sem qualquer conotação negativa a não ser pelo contexto no restante na frase), o transmissor afirmar "Os rolhas-de-poço..." seria um disfemismo. Evidentemente, xingamentos e termos pejorativos têm em nada a contribuir para a comunicação empática.

Por sua vez, a Hipérbole - “[...] recurso de expressão pelo qual se engrandece ou diminui de forma exagerada uma afirmação" (ALMEIDA, 2010, p. 478) - também não está em sincronia com a comunicação proposta por Marshall Rosenberg. Exagerar na exposição de um problema faz esse problema maior e torna hercúleo resolvê-lo. Na suposição em que uma mãe encontra seu filho após um longo período de busca em um Shopping, esbravejar "Te procurei mais de mil vezes, onde você estava?!" não fará o filho se sensibilizar e compreender o posicionamento de sua mãe. Por lógica, ele deduz que ela não deve tê-lo procurado "mais de mil vezes", e reconhece o recurso figurado como um exagero. Assim, considerará que a mãe está fazendo tempestade em um copo d'água, e não que ela tem uma necessidade legítima, ou que há um problema sério sobre o qual se deva resolver. Se a mãe transmitisse uma mensagem mais límpida e sincera, sem a conotação anterior, como em "Eu procurei você em 
vários pontos do Shopping, fiquei preocupada em te perder de verdade", ela estaria transmitindo suas emoções (a preocupação, o medo, a angústia, p.ex.) e suas necessidades. $\mathrm{O}$ filho, por empatia, compreenderia os sentimentos da mãe e, com essa linguagem sincera, estaria mais provável a mudar o comportamento para uma atitude que mantenha seu interesse (por exemplo, em ver diversas lojas de brinquedos), mas que não prejudique a outra pessoa (pedir que a mãe pare de ver suas lojas e o acompanhe, ou ir com um responsável, ou ir sozinho mas não longe do horizonte materno).

Por fim, atenta-se ao vulgarismo. Segundo Afrânio Garcia, "abrangeria apenas os palavrões e as palavras decididamente ofensivas e grosseiras. Pode ser usado estilisticamente, para evidenciar o tipo de relações numa determinada comunidade". Cita-se o exemplo "Vá te catar!".

\subsection{Outras considerações sobre a linguagem verbal}

Para Rosenberg (2006, p. 103), "Em primeiro lugar, devemos expressar o que estamos pedindo, e não o que não estamos pedindo". Assim, em um contexto de conflito, o vocábulo "não" seria mais bem substituído por uma expressão positiva.

Além dos advérbios de negação, devem-se evitar os advérbios de intensidade e frequência, como "demais", "pouco", "muito", "sempre", "nunca" e afins: "Palavras como freqüentemente e raramente também podem contribuir para confundir observação com avaliação" (ROSENBERG, 2006, p. 57).

\section{Aspectos para uma linguagem corporal não-violenta}

A linguagem corporal é aquela comunicação empreendida por meio de gestos, posturas e expressões faciais. Pelos estudos da linguagem, tradicionalmente a linguagem corporal se divide em fechada (que envia sinais de inimizade, hostilidade, agressividade, desconforto e desinteresse) e aberta (que transmite afinidade, hospitalidade, intimidade, interesse, conforto e paz). Neste trabalho, entendemos a linguagem corporal fechada como uma comunicação violenta e, a aberta, como a CNV.

Aqui, não se analisa a linguagem corporal com o intuito de saber o que alguém está sentindo ou se está mentindo. Esses jogos mentais não são o escopo do presente trabalho. É importante entender quando manifestamos uma linguagem corporal violenta porque quem observa irá se sentir violentado pela nossa linguagem. Muitas vezes, exaltamo-nos quando conversamos com alguém de maneira séria e esta nos olha com expressão facial emburrada, 
ou ignora contato visual, ou se atira na cadeira com os braços cruzados. Isto é porque a hostilidade e a agressividade nos foram comunicadas - a linguagem Chacal.

Nesse sentido, podemos expressar a linguagem corporal de forma consciente (quando adotamos uma postura ou gesticulação para transmitir uma informação que queremos) ou inconsciente, por estarmos acostumados (pelo convívio social, hábitos culturais e representações artísticas, p.ex.) a essa performatividade em determinados contextos.

Segundo Pires, Lage e Hartalian (2004, p. 48), a linguagem corporal fechada, aqui compreendida por comunicação violenta, é manifestada através dos seguintes sinais (e seus respectivos significados):

AGRESSIVO: corpo inclinado para frente; apontando com o dedo; punhos fechados.

DEFENSIVO: os pés apontando para dentro; mãos fechadas.

“DEIXE-ME FALAR!”: batendo os dedos na mesa; batendo os pés; encarando.

PROVOCADOR: mão na cintura; franzir as sobrancelhas mostrando desagrado.

REJEITANDO...: afastando o corpo; braços cruzados; pernas cruzadas; olhar para o chão.

Mediadores, conciliadores e demais envolvidos em métodos autocompositivos de resolução de conflitos, que costumam realizar audiências judiciais ou extrajudiciais, provavelmente já observaram conflitantes (desinteressados ou cépticos com esses métodos) não cooperarem, sentarem-se de costas para o outro participante e/ou manifestarem os sinais descritos no texto supracitado. Essa performance é um exemplo de linguagem corporal violenta, normalmente seguida de linguagens verbais também violentas. O outro partícipe, que inicialmente não foi violento com seu corpo, muitas vezes "perde a cabeça" com tais atitudes e também recorre à linguagem violenta, seja ela verbal ou não.

Conforme Pease e Pease (2005, p. 20), especificamente quanto à gesticulação, “A palma fechada em um punho, com o dedo assinalando a direção, é o plano simbólico com que um ordena ao que o escuta para fazer que lhe obedeça”. Apontar com o dedo indicador, muitas vezes em movimentos rápidos e longos, é uma linguagem corporal extremamente violenta, conforme demonstrado no último desenho da Figura 1. 
RELACult - Revista Latino-Americana de Estudos em Cultura e Sociedade

Revista Latinoamericana de Estudios en Cultura y Sociedad | Latin American Journal of Studies in Culture and Society V. 05, ed. especial, abr., 2019, artigo no 1304 | claec.org/relacult | e-ISSN: 2525-7870
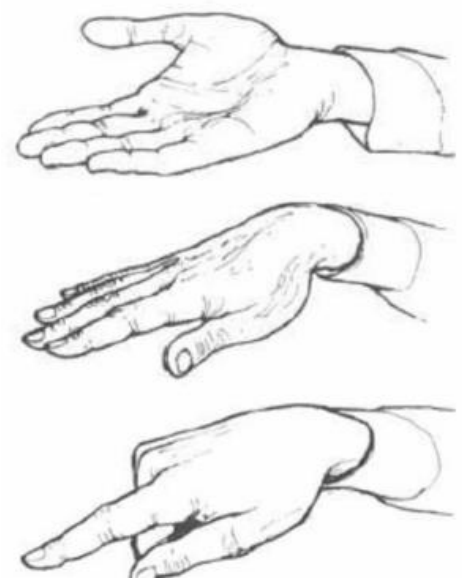

Figura 1 - Três gestos principais com as palmas.

Fonte: PEASE; PEASE, 2005, p. 20.

Para Pierre Weil e Roland Tompakow (1989, p. 70), o gesto com o indicador ereto transmite a mensagem de acusação ou ameaça:

\section{ACUSAÇÃo}

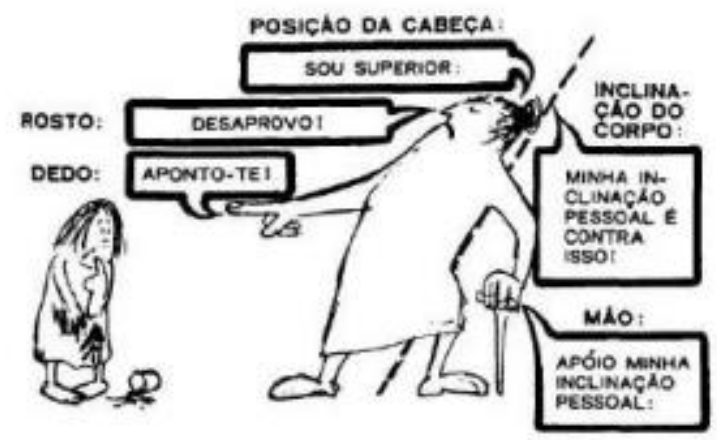

\section{AMEAÇA}

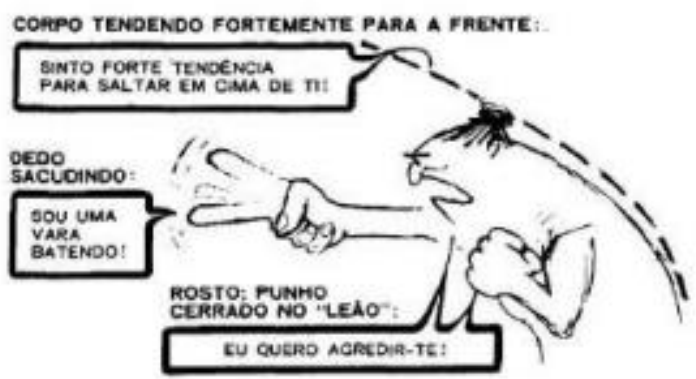

Figura 2 - Linguagem corporal violenta com o dedo indicador.

Fonte: WEIL; TOMPAKOW, 1989, p. 70. 
Também se faz ressalvas, para o advento da CNV, de uma postura com os braços cruzados e polegares para cima, conforme mesmos autores:

Outra posição conhecida é a dos braços cruzados com os polegares para cima. É um sinal duplo pois os braços indicam uma atitude defensiva ou negativa, enquanto que os polegares representam uma atitude de superioridade. A pessoa que usa este gesto duplo está acostumado a gesticular com os polegares e, quando está parada, se balança sobre os pés (PEASE; PEASE, 2005, p. 27).

Logicamente, seria bastante difícil conseguir se expor de forma calma e compassiva, sem acudir à violência, e sem se sentir ofendido, com alguém que esteja sentado à frente do comunicador em uma postura similar à da Figura 3 (abaixo).

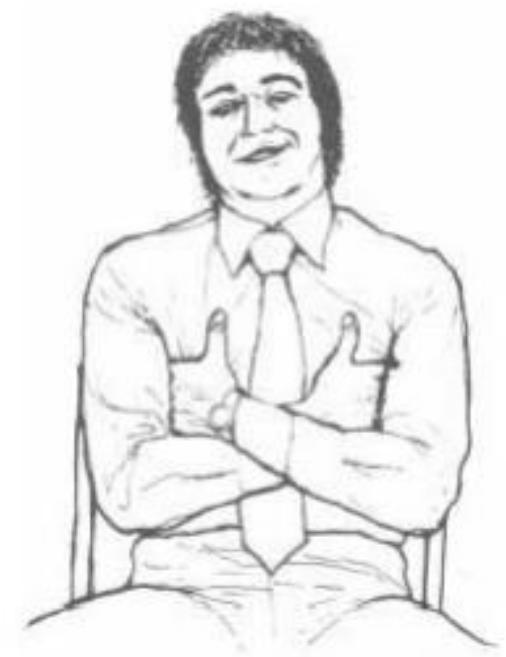

Figura 3 - Corpo com os braços cruzados e polegares para cima.

Fonte: PEASE; PEASE, 2005, p. 27.

Os braços cruzados também motivam outro exemplo prático de postura violenta (PEASE; PEASE, op. cit., pp. 34-5):

Ao cruzar um ou os dois braços sobre o peito se forma uma barreira que, em essência, é a tentativa de deixar fora de nós a ameaça pendente ou as circunstâncias indesejáveis. Quando uma pessoa tem uma atitude defensiva, negativa ou nervosa, cruzar os braços demonstra que se sente ameaçada.

Se, além de ter cruzado os braços, a pessoa fechou os punhos, os sinais são de defesa e hostilidade. Este grupo de gestos se combina às vezes com dentes apertados e rosto avermelhado. Nesse caso, pode ser iminente um ataque verbal ou físico.

Mais uma vez, é evidente que a seguinte (Figura 4) postura não é convidativa para solucionar um conflito, nem uma forma de escutar ativamente o outro, algo tão importante para expressar empatia: 
RELACult - Revista Latino-Americana de Estudos em Cultura e Sociedade

Revista Latinoamericana de Estudios en Cultura y Sociedad | Latin American Journal of Studies in Culture and Society V. 05, ed. especial, abr., 2019, artigo no 1304 | claec.org/relacult |e-ISSN: 2525-7870

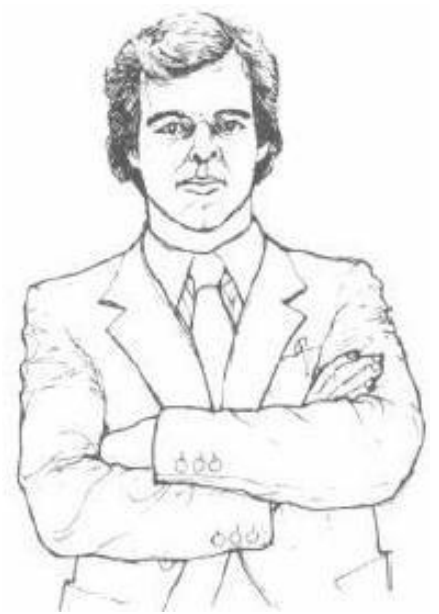

Figura 4 - Escuta agressiva com os braços cruzados.

Fonte: PEASE; PEASE, 2005, p. 34.

Weil e Tompakow (1989) concordam sobre a agressividade da postura dos braços cruzados, conforme Figuras 5 e 6:

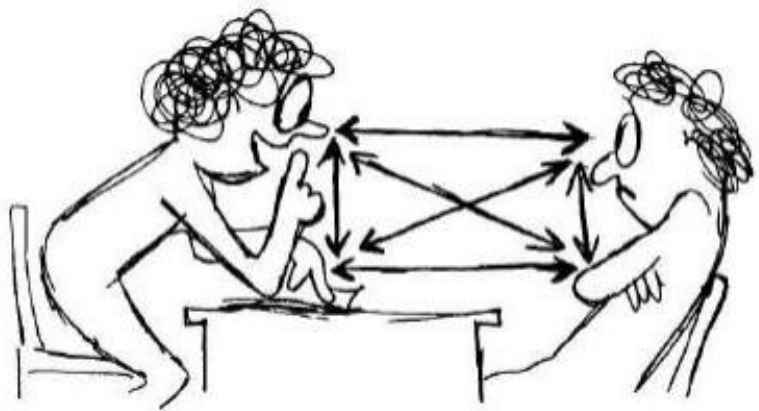

Figura 5 - Escuta desinteressada com os braços cruzados.

Fonte: WEIL; TOMPAKOW, 1989, p. 45.

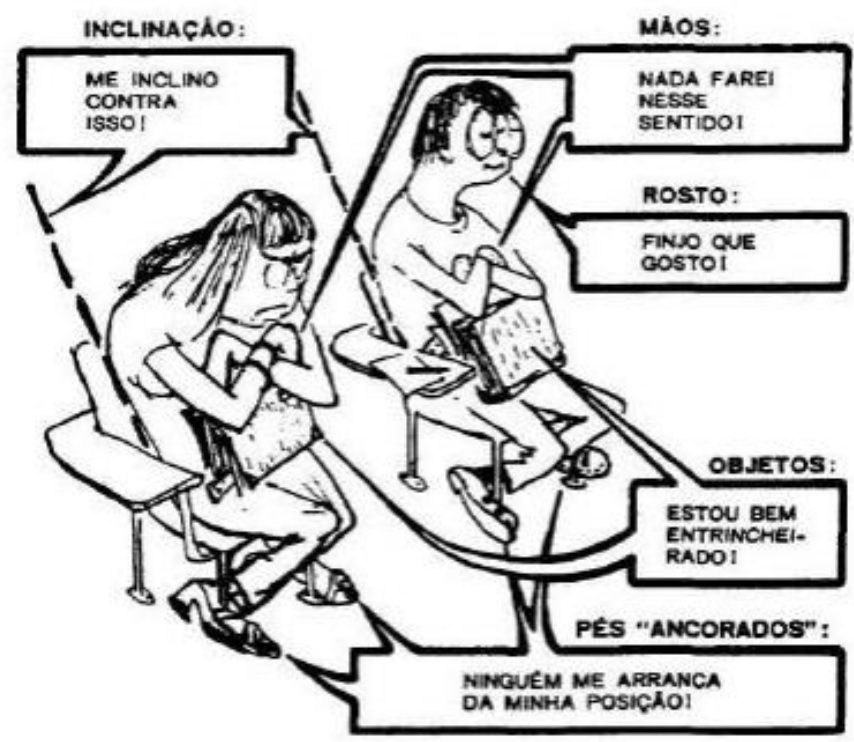

Figura 6 - Escuta desinteressada com os braços cruzados.

Fonte: WEIL; TOMPAKOW, 1989, p. 63. 
Ademais, a escuta ativa, princípio fundamental da comunicação não violenta, precisa ser demonstrada na nossa linguagem corporal. Um exemplo oposto disso é "Quando o que [pessoa] está escutando começa a apoiar a cabeça na mão" (PEASE; PEASE, 2005, p. 32), caso em que está dando sinais de aborrecimento, o que desmotiva a comunicação.

Além disso, para a promoção da escuta ativa, e para o comunicador sentir que está sendo ouvido e recebe atenção, é fundamental o contato visual. Nesse contexto, elucida Pease e Pease (op. cit., p. 37):

Provavelmente, o ponto mais importante da comunicação facial encontraremos nos olhos, o foco mais expressivo da face. O contato ocular é um sinal chave em nossa comunicação com outros. Assim, a longitude do olhar, quer dizer, a duração do contato ininterrupto entre os olhares, sugere uma união de mensagens.

Importante salutar que para os autores (PEASE; PEASE, 2005, p. 39), devemos interpretar os sinais corporais em um contexto completo, pois um único sinal (como o cruzamento de pernas) pode não significar defesa ou negação, pois muitas pessoas se acostumam a se comportar socialmente assim, sendo um hábito de etiqueta, sobretudo entre mulheres.

Quanto à fisionomia, um mau exemplo de linguagem corporal é inclinar a cabeça para baixo, o que assinala atitude negativa e até mesmo oposta ao pensamento que o interlocutor está informando (PEASE; PEASE, 2005, p. 42). Segue a Figura 7:
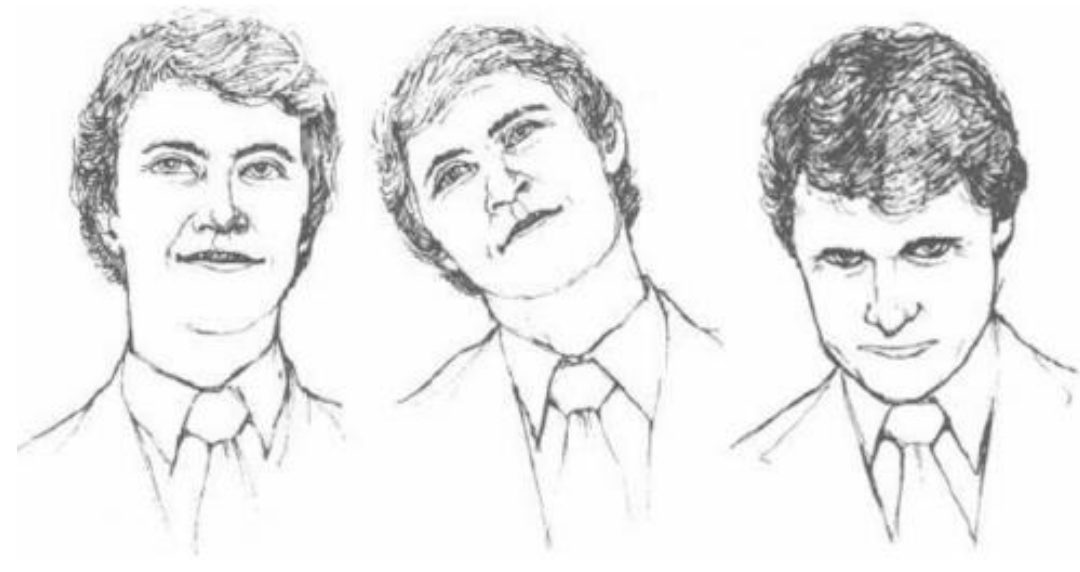

Figura 7 - Escuta agressiva com cabeça inclinada (terceiro desenho).

Fonte: PEASE; PEASE, 2005, p. 42.

\section{Conclusões}

Ante o exposto, conclui-se que os estudos da linguagem são muito importantes para um entendimento mais completo da comunicação não violenta (CNV), método de Marshall Rosenberg. Embora o autor tenha estabelecido algumas conexões entre o método e a 
Linguística no livro Comunicação Não Violenta: técnicas para aprimorar relacionamentos pessoais $e$ interpessoais, muitos pontos não foram aprofundados, o que impulsionou o presente trabalho.

Em síntese, algumas estruturas frasais na linguagem verbal devem ser evitadas pelos adeptos da comunicação empática, como verbos e locuções verbais específicos ("ter de“, "ter de fazer", "fazer-me" e "dever"), adjetivos, a construção textual Sujeito + verbo "Ser" + adjetivo, locuções comparativas ("tão... quanto", "mais... (do) que", "menos... (do) que", "melhor (do) que", "pior (do que)", "tal qual", "tal como", "tanto quanto" e "que nem") e algumas figuras de linguagem (Símile, Metáfora, Antífrase ou Ironia, Disfemismo, Hipérbole e o vulgarismo).

A linguagem não-verbal, representada pelo corpo em gestos, expressões faciais e postura, também pode ser uma comunicação Chacal. Trata-se da linguagem corporal fechada, que ocorre em braços cruzados, dedo indicador ereto em punho fechado e cabeça inclinada para frente, dentre outras situações.

Finalmente, é evidente que este artigo está longe de esgotar todas as possibilidades de estruturas frasais da linguagem verbal e aspectos da linguagem corporal que possam ser violentos. Mesmo assim, algumas noções básicas, gerais e introdutórias foram apresentadas.

\section{Referências}

ALMEIDA, N. T. Gramática da Língua Portuguesa para concursos, vestibulares, ENEM, colégios técnicos e militares...: com inúmeros exercícios resolvidos de diversos vestibulares e concursos públicos. 9. ed. rev. e atual. conforme a nova ortografia e de acordo com o Vocabulário Ortográfico da Língua Portuguesa - Volp. 4 tiragem. São Paulo: Saraiva, 2010.

CRYSTAL, D. A dictionary of linguistics and phonetics. 6th. ed. Oxford, UK: Blackwell Publishing, 2008. (The Language Library Series). Disponível em: https://anekawarnapendidikan.files.wordpress.com/2014/04/a-dictionary-of-linguistics-andphonetics-by-david-christal.pdf. Acesso em 15 janeiro 2018.

GARCIA, A. Figuras de Linguagem e Ensino. Filologia, s/d. Disponível em: http://www.filologia.org.br/viiisenefil/03.html. Acesso em 15 janeiro 2018.

OTSUKA, D. Disfemismo. Info Escola, 2010. Disponível em: https://www.infoescola.com/linguistica/disfemismo/. Acesso em 15 janeiro 2018.

PASCHOALIN, M. A.; SPADOTO, N. T. Gramática: teoria e exercícios. Ed. renovada. São Paulo: FTD, 2008.

PEASE, A.; PEASE, B. Desvendando os segredos da linguagem corporal. Rio de Janeiro: Sextante, 2005. Disponível em: 
http://www.vazzi.pro.br/ sitevelho/arquivos/biblioteca/e book/Allan\%20e\%20Barbara\%2 0Pease\%20-\%20Desvendando\%20os\%20Segredos.pdf. Acesso em 15 janeiro 2018.

PIRES, Ana Carolina; LAGE, Danielle; HARTALIAN, Natalia. O Corpo Fala: A importância de gestos em entrevistas e dinâmicas de grupo. In: Eclética (Revista dos alunos do Departamento de Comunicação Social da PUC-Rio), Ano 8, n. 16, jan./jun. 2003, pp. 458 .

ROSENBERG, M. B. Comunicação não-violenta: técnicas para aprimorar relacionamentos pessoais e profissionais. 2. ed. São Paulo: Ágora, 2006.

WEIL, P.; TOMPAKOW, R. O Corpo Fala: a linguagem silenciosa da comunicação nãoverbal. 74. ed. Rio de Janeiro: Vozes, 1989. 